\title{
Comparison of Myoinositol versus Combination of Metformin and Myoinositol in Ovulation Induction in Polycystic Ovarian Syndrome
}

\author{
TANWEER AKHTAR ${ }^{1}$, FOZIA SHAIKH ${ }^{2}$, BASMA ${ }^{3}$, WAQAR-UN-NISA AHMED ${ }^{4}$, SHAISTA LASHARI ${ }^{5}$, NAJIA BHATTI ${ }^{6}$ \\ ${ }^{1}$ Associate Professor, ${ }^{3,6}$ Assistant Professors, ${ }^{4,5}$ Senior Registrars, Department of Obstetrics \& Gynaecology, Shaikh Zayed Women \\ Hospital, Shaheed Mohtarma Benazir Bhutto Medical University, Larkana \\ ${ }^{2}$ Assistant Professor of Obstetrics \& Gynaecology, Shaheed Mohtarma Benazir Bhutto Medical University, Larkana \\ Correspondence to: Dr. Tanweer Akhtar, E-mail: tanweerali74@yahoo.com Cell: 0335-3534077
}

\begin{abstract}
Objective: To compare the efficacy of insulin sensitizer myoinositol versus a combination of myoinositol plus metformin for ovulation induction in polycystic ovarian syndrome.

Study Design: Prospective, randomize control trail.

Place \& Duration of Study: Department of Obstetrics \& Gynaecology, Sheikh Zayed Women Hospital Larkana from $1^{\text {st }}$ January 2017 to $31^{\text {st }}$ December 2017.

Methodology: Sixty patients were recruited. The proper clinical history, demographic and physical examinations were recorded. Sixty patient divided in two groups A and B, each group receive 30 patients. Group A received myoinositol $1 \mathrm{gm}$ twice daily plus ovulation (letrozole +gonadotrophin) and Group B received two insulin sensitizer myoinositol and metformin plus ovulation induction protocol(from 2-6 days and 7-9 days. Transvaginal ultrasound performed on day 12 of all patients to see the follicular size.

Results: Mean age of participants was $26.4 \pm 4.4$ years and LH/FSH ratio was $>1.5$. Oligomenorrhea, infertility, hirsutism, and overweight were the major clinical manifestation of women with PCOs. Twenty nine women with PCOs of group A (metformin plus myoinositol) were increased number of follicles as compared to women of group $B$ (myoinositol alone), the difference was statistically significant $(p<0.05)$.

Conclusion: The combination of these two drugs 'Metformin and Myoinositol', work synergistically that gives more metabolic and reproductive benefits as compared to single drug work alone.

Keywords: Polycystic ovarian syndrome, Ovulation, Metformin, Myoinositol, Insulin sensitivity
\end{abstract}

\section{INTRODUCTION}

Polycystic ovarian syndrome is an endocrine metabolic disorder affecting 5-10 percent of women, characterized by hyperinsulinemia hyperandrogenism, hirsutism, ovarian dysfunction and (anovulation) oligomenorrhea and is a common cause of infertility. ${ }^{1}$ Diagnosis of PCOS depends upon clinical and biochemical and pathological characteristic and vary according to race-ethnicity. ${ }^{2}$ Insulin resistance and hyperinsulinemia are frequently found in PCOS women in obese it is $65 \%$ and in lean it is $20 \%$. Insulin resistance in PCOS is due steroidogenesis from the ovary, this abnormal steroid genesis leads to anovulation and hirsutism, patients with PCOS may develop type II diabetes in later of their life. ${ }^{3}$ Because of insulin, resistance in PCOS - insulin-sensitizing agents improve the metabolic and hormonal impact of PCOS by increasing insulin activity. Metformin being used in this regards since long, and established its efficacy, but is effects synergies when inositol also added. Metformin reduces the level of LH decrease hyperinsulinemia and ultimately less production of androgen. ${ }^{4}$

Inositol isoform is a vitamin B complex a food nutrition free myoinositol produced by all eukaryotic cells. It accelerates the dehydrate sporulation of glycogen synthesize and pyruvate dehydrogenase utilization and increase the sensitivity of insulin action, by enhancing insulin sensitivity with that two modulator parameter of PCOS improve especially ovulation. ${ }^{5}$

Ovulation induction in PCOS patient becomes an art where we found not only increase insulin resistance but some ovulatory agents like clomiphene citrate also being resistance. ${ }^{6}$ So, we used letrozole and gonadotrophin as an ovulation induction agent aim of this study is to determine the efficacy of insulin sensitizer single-agent versus combination of agents in ovulation induction of PCOS patient.

\section{MATERIALS AND METHODS}

This prospective, randomized control trial was conducted at Sheikh Zayed Women Hospital Larkana from $1^{\text {st }}$ January 2017 to $31^{\text {st }}$ December 2017 . Sixty pregnant women with PCOs were recruited in this study. After taken consent form, age, clinical features, and laboratory testing have collected through a questionnaire. Sixty patients were divided in two groups; Group A patients received myoinositol (1gm/day), metformin (500mg twice a day daily), for ovulation induction: letrozole $(2.5 \mathrm{mg}$ twice a day from day 2-6), Gonadotrophin (human menopausal gonadotrophin 75IU intramuscular on day 7-9). Group B patients received myoinositol (1gm/day), for ovulation induction: letrozole (2.5 $\mathrm{mg}$ twice a day from day 2-6), Gonadotrophin (human menopausal gonadotrophin 75IU intramuscular on day 7-9). Patients of both groups recalled on day 12 for transvaginal ultrasound for follicular size. The data was entered and analyzed through SPSS-20. Chisquare is used to find out the association of follicles between drugs group.

\section{RESULTS}

The mean age and $\mathrm{LH} / \mathrm{FSH}$ ratio were $26.4 \pm 4.4$ years and $1.3 \pm 0.3$ respectively (Table 1 ). $98 \%$ women presented the sign of jaundice. Twenty (33.3\%) was acne, 44 (73.3\%) was oligomenorrhea, 32 (53.3\%) was overweight and only $12(20 \%)$ was hirsutism (Table2). All the participants received letrozole on day 2- 6 and gonadotrophins on day 6 
and 7 for ovulation induction. Out of 30, 29 participants of group A (metformin + myoinositol) having follicles in their ovary whereas only 14 participants of group B (myoinositol) having follicles. P-value is less than 0.05 which is statistically significant (Table 3).

Table 1: Descriptive statistics of the women $(n=60)$

\begin{tabular}{|l|l|}
\hline Variable & Mean \pm SD \\
\hline Age (years) & $26.42 \pm 4.42$ \\
\hline LH/FSH ratio & $1.36 \pm 0.31$ \\
\hline FSH & $7.98 \pm 2.28$ \\
\hline LH & $10.64 \pm 3.10$ \\
\hline
\end{tabular}

Table 2: Frequency of clinical characteristics $(n=60)$

\begin{tabular}{|l|l|l|}
\hline Variable & No. & $\%$ \\
\hline Acne & 40 & 66.7 \\
\hline No & 20 & 33.3 \\
\hline Yes & \multicolumn{2}{|l|}{} \\
\hline Oligomenorrhea & 16 & 26.7 \\
\hline No & 44 & 73.3 \\
\hline Yes & 1 & 1.7 \\
\hline Infertility & 59 & 98.3 \\
\hline No & \multicolumn{2}{|l|}{} \\
\hline Yes & 28 & 46.7 \\
\hline Over-weight & 32 & 53.3 \\
\hline No & \multicolumn{2}{|l|}{} \\
\hline Yes & 48 & 80 \\
\hline Hirsutism & 12 & 20 \\
\hline No & \\
\hline Yes &
\end{tabular}

Table 3: Association between drug status and follicles

\begin{tabular}{|l|l|l|l|}
\hline Follicles & Group A & Group B & P value \\
\hline Yes & 29 & 14 & \multirow{2}{*}{$\mathrm{P}<0.05$} \\
\hline No & 1 & 16 & \\
\hline
\end{tabular}

\section{DISCUSSION}

Polycystic ovary syndrome (PCOS) is the most common endocrine situation categorized by Oligomenorrhea or anovulatory infertility. It contributes about $15-20 \%$ among infertile women. Researchers found that PCOS with central obesity was about $80 \%$ due to insulin resistance and $40 \%$ in lean women. PCOS doesn't distress only reproductive system but also play a major role in long term disturbance in a metabolic disorder like diabetic mellitus and cardiovascular disorder. ${ }^{7}$

In the present study, mean age of study participants was 26.4 years. LH/FSH ratio was $>1.5$ (Table 1 ). Many researchers found that $\mathrm{LH} / \mathrm{FSH}$ ratio is the prognostic factor. These two hormones are released under the influence of $\mathrm{GnRH}$ which is act on B-cells of the anterior pituitary. LH in female play a major role in androgen production whereas FSH with help of aromatase enzyme work on the conversion of androgens to estrogen. The balance between $\mathrm{LH}$ and $\mathrm{FSH}$ is essential for follicular development. If any imbalance between these two ratios increases the amount of androgen leads to degeneration of follicles and anovulation. Patients with PCOS patients having $\mathrm{LH} / \mathrm{FSH}$ ratio is $>1.5$ and decrease pregnancy rate. ${ }^{8}$ A randomized controlled trial was conducted at India, revealed that the women with PCOS were young and having in their fertile age 28.1 years 4. Another study revealed that patients with $\mathrm{PCO}$ s having an increased level of $\mathrm{LH}$ and variability of $\mathrm{LH} / \mathrm{FSH}$ ratio. ${ }^{9}$
The present study showed that hirsutism, overweight and oligomenorrhea were a major clinical characteristic of a patient with PCOS (Table 2). The characteristic feature of PCOS is heterogeneous that differs according to overweight, acne, hirsutism, infertility with diabetes and different malignancy. The past study revealed that obesity and insulin resistance wasa major factor of a patient with PCOS. ${ }^{10}$ Another research concluded that the presence of hirsutism, Oligomenorrhea, amenorrhea, hypertension, weight gain, and acne were significantly associated with women having PCOS. ${ }^{11}$

Myoinositol and metformin are insulin-sensitizing drugs which have been studied to evaluate their properties on PCOS sign and symptoms in order to find out the probability of improving fertility and reproductive consequences. Myoinositol is a major secondary messenger of $\mathrm{FSH}$ and $\mathrm{LH}$ by control of intracellular $\mathrm{Ca2+}$ release which is directly impacting on ovulation. Whereas, the primary act of metformin is not only lower high parameters like insulin, androgens and free $T$ levels but also increase levels of sex hormone-binding globulin (SHBG) and insulin-like growth factor-binding protein (IGFBP) by suppression of hepatic glucose production. All these factors lead to improve menstrual frequency, ovulation, fertility and live birth. The present study showed that group A (metformin plus myoinositol) having a large number of follicles in their ovaries as compared to group $B$ which having myoinositol alone (Table 3 ). The result is statistically significant. Researchers found that the effectiveness of metformin shows individual differences in PCOS patients. Another study revealed that two insulinsensitizers (metformin and myoinositol) were lower body mass, sensitivity towards insulin and improve menstrual cycle. ${ }^{12}$ This study reviewed that metformin plays an important role in increasing the live birth rate among women undergoing ovulation induction with gonadotrophins and increase the number of follicles in ovaries. ${ }^{13}$ In order to find out that which one is more useful and beneficial is still an ongoing debate.

\section{CONCLUSION}

The combination of these two drugs 'metformin and myoinositol' work synergistically that give more metabolic and reproductive benefits as compared to single drug work alone.

\section{REFERENCES}

1. Dumesic DA, Oberfield SE, Stener-Victorin E, Marshall JC, Laven JS, Legro RS. Scientific statement on the diagnostic criteria, epidemiology, pathophysiology, and molecular genetics of polycystic ovary syndrome. Endocr Rev 2015; 36: 487-525.

2. Teede H, Deeks A, Moran L. Polycystic ovary syndrome: a complex condition with psychological, reproductive and metabolic manifestations that impacts on health across the lifespan. BMC Med 2010; 8: 41.

3. Bevilacqua A, Dragotto J, Giuliani A, Bizzarri M. Myoinositol and $D$-chiroinositol $(40: 1)$ reverse histological and functional features of polycystic ovary syndrome in a mouse model. $J$ Cell Physiol 2019; 234: 9387-98.

4. Ou HT, Chen PC, Wu MH, Lin CY. Metformin improved health-related quality of life in ethnic chinese women with polycystic ovary syndrome. Health Qual Life Outcomes 2016; 14: 119. 
5. Laganà AS, Garzon S, Casarin J, Franchi M, Ghezzi F. Inositol in polycystic ovary syndrome: restoring fertility through a pathophysiology-based approach. Trends Endocrinol Metab 2018.

6. Freire A, Gryngarten M, Ballerini MG, Arcari A, Bengolea V, Scaglia $\mathrm{P}$, et al. Adiponectin as a marker of peripheral insulin resistance in adolescents with polycystic ovarian syndrome (PCOS) and as a tool to suspect insulin receptor defects. Hormone Res Paediatr 2018; 90: 566-9.

7. Hassani F, Oryan S, Eftekhari-Yazdi P, Bazrgar M, Moini A, Nasiri $\mathrm{N}$, et al. Downregulation of extracellular matrix and cell adhesion molecules in cumulus cells of infertile polycystic ovary syndrome women with and without insulin resistance. Cell J (Yakhteh) 2019;21(1).

8. Agrawal A, Mahey R, Kachhawa G, Khadgawat R, Vanamail $P$, Kriplani A. Comparison of metformin plus myoinositol vs metformin alone in PCOS women undergoing ovulation induction cycles: randomized controlled trial. Gynecol Endocrinol 2019; 2:1-4.
9. Malini NA, George KR. Evaluation of different ranges of $\mathrm{LH}: \mathrm{FSH}$ ratios in polycystic ovarian syndrome (PCOS) clinical based case-control study. Gen Comparative Endocrinol 2018; 260:51-7.

10. Revathi R, Julius A. Effect of LH/FSH Ratio and its Correlation with Insulin Resistance in PCOS Obese woman of Reproductive age Group. Res J Pharmacy Technol 2018; 11(6):2217-9.

11. Pal L, Pathy S. Polycystic ovarian syndrome. Evidencebased Obstet Gynecol 2019; 9: 117-29.

12. Fruzzetti $F$, Perini $D$, Russo $M$, et al. Comparison of two insulin sensitizers, metformin and myo-inositol, in women with polycystic ovary syndrome (PCOS). Gynecol Endocrinol 2017; 33:39-42.

13. Bordewijk EM, Nahuis M, Costello MF, et al. Metformin during ovulation induction with gonadotrophins followed by timed intercourse or intrauterine insemination for subfertility associated with polycystic ovary syndrome. Cochrane Database Syst Rev 2017; 24: CD009090. 